\title{
THE CULTURAL ROLE OF TEACHERS IN THE LIGHT OF SUSTAINABLE PROFESSIONAL DEVELOPMENT FOR HERITAGE PRESERVATION
}

Alaa Ali Muhammad FARIS *

Faculty of Art Education, Helwan University, Egypt

\begin{abstract}
This research aims to identify the cultural role of teachers in the field of professional development in order to preserve the heritage from the viewpoint of education experts and the sources of activating the cultural role of teachers in the field of sustainable professional development in order to preserve the heritage, using the descriptive approach, on a basic sample of (400) (Teacher), (20) directors and agents, and (10) education experts, were chosen randomly, and the most important results confirmed that one of the most important sources of activating the cultural role of teachers is the provision of sustainable professional development programs for working teachers and student teachers in the College of Education that contain the cultural dimension related to heritage.

Keywords

Multi-Sensory Experience, Embodied Cognition, The Scaffolded Mind, Exaptation, Conceptual Knowledge, Multi-Sensory Experience, Global Markets.
\end{abstract}

\section{Introduction}

The role of the teacher in the twenty-first century is considered one of the roles that have overlapped and integrated among themselves, so it is no longer a session limited to indoctrination and education in the traditional way, but rather exceeded that to include the role of the educator, the qualifier, the wave and the mentor, and given the position that the teacher enjoys and the great role in the educational process and the development that accompanies the profession Education, the need requires teacher development and cultural development in addition to academic and educational development, and in light of cultural changes, the cultural formation of the teacher is one of the important things that help him in the performance of his profession and provide society with members who are educated who can live with the rapid cultural change in our contemporary world.

Education for sustainable development requires the addition of new roles for the teacher, such as the cultural role to achieve adaptation to the requirements of society and its advancement, and for this to be achieved, the cultural role of the teacher must increase its effectiveness in performing his true mission in education. UNESCO emphasized that education is a major factor and an important tool for achieving development. | Sustainable in all its forms and dimensions. Therefore, the teacher must acquire many cultural knowledge, skills and competencies that enhance the cultural course in addressing these challenges that would lose the community's

*Corresponding author: art_education@helwan.com 
value, principles and cultural identity, and for the teacher to be able to implement this role and achieve it, sustainable development programs must be available in all its axes.

In addition, heritage is the distinct embodiment of a society's culture in a period of time, and it is that valuable stock that is distinguished by persistence and continuity, and which combines its aspects aesthetic and spiritual values, in addition to being an existing material fact that imposed its acceptance and respect among societies. Heritage from the cultural point of view represents the reference and the material evidence Based on the specificity of the society's culture, the unity of its human and intellectual features, and its historical dimensions, and from the environmental point of view, the heritage represents a sincere woman who reflects the dimensions of the place, its features and its environmental features.

\section{Research problem}

Through the work of the researcher, the head of the final review teams at the National Authority for Quality Assurance, in the Arab Republic of Egypt, and through the review of (20) preuniversity education institutions in various stages, it was found that the second field (leadership and governance), which includes the practice that carries the code (2-3) 2-3) which states (The leadership activates a system for sustainable professional development), and the fifth field (Quality Assurance) which includes the practice that carries a code (5-1-1-2) and which states (The training unit activates sustainable professional development programs) By examining the documents of these two practices, it was found that only sustainable professional development programs are available for the specialized academic axis and the educational axis only, while in the ninth field (educational climate) an indicator bearing a code $(-r-r)$ containing practitioners and which is available in the institution climate Supportive of culture and that this indicator did not obtain any positive estimates and no documents were available, and the teacher's professional academy is responsible for sustainable professional development programs for teachers, which aim to prepare the teacher in two main axes, namely the specialized academic axis, which is teacher development in his first major. Academic, and the focus of the behavioral educational field, which is working to provide the teacher with the necessary behavioral skills (planning, teaching methods, evaluation methods, learning theories, teaching strategies) the general framework for a sustainable professional development policy for teachers at the Ministry of Education in the Arab Republic of Egypt.

The researcher conducted an exploratory study (1) by interviewing (5) experts of sustainable professional development in the field of education at the Ministry of Education in the Arab Republic of Egypt, aimed at monitoring the reality of the axes of sustainable professional development among teachers, and identifying the most important axes that should be added to 
professional development programs The results of this study resulted in the Ministry of Education in the Arab Republic of Egypt working through two axes, namely the academic axis and the educational axis, and their agreement at a rate of (100\%). The axis of culture in general must be added, and the axis of culture related to heritage in particular to enhance identity and inherit the principle of citizenship

And through the exploratory study, which aimed to identify the most important axes of professional development that should be added from the teachers' point of view, their number was (500) teachers at a percentage $(5 \%)$ of the total teachers in the Directorate of Education in Port Said Governorate from the primary, middle and secondary levels, and its results resulted in $(20) \%$ ) Supported adding the cultural dimension .

The researcher conducted a survey study aimed at identifying the level of the cultural role that teachers play in light of sustainable professional development for the sake of preserving heritage (directors and agents) and their number (45) percentage (5\%) of the total directors and agents in the Directorate of Education in the Governorate Port Said from the elementary, middle and high school levels, and its results resulted in a weak level of the cultural role of teachers.

Based on the foregoing and through the researcher's knowledge of the quality literature and some related studies such as: studying each of: Al Mohsen (2014), "Khawaldeh and others" (2012), “UNESCO (2012),“ Editorial Board ”(2012),“ Al-Sisi (2008), “Al-Shehri” (2008), “Ghashem (2008), Al-Usaimi, (2014),“ Villan Heli, ”(2010),“ HarshaDhar and Shashirekha, ”(2008)“ Council of, (2009) " Corney Graham ”, (2012)“ Mshebila ”, 2013“ Ministers of Education (2012). All these studies indicate that cultural preparation for teachers is one of the most important requirements for sustainable professional development.

In addition to the accumulated experiences of the researcher in the field of education, training, quality and communication with some educational experts in the field of sustainable professional development, and academics in the field of culture and heritage, who emphasized the necessity of adding the cultural dimension in sustainable professional development programs for teachers, and the dissemination of cultural values and the identity of society is done through education Through a teacher who requires a high level of knowledge of a society's culture and cultural challenges, where comprehensive and sustainable development of society cannot be achieved without an education that accommodates contemporary and urgent changes, so the problem crystallized in the neglect of the cultural axis in the sustainable professional development programs for the teacher and therefore the researcher has The strong desire to conduct this study where scientific results can be reached that may contribute to 
achieving the activation of the cultural role of teachers in light of sustainable professional development for the sake of preserving the heritage, as they are one of the sources of cultural transmission to students for which it creates a generation that values the value of heritage.

\section{Study population:}

The study population is represented by experts in the field of sustainable professional development from the employees of the Teacher Professional Academy in the Arab Republic of Egypt, as well as teachers and agents in the different pre-university education stages.

\section{The study sample:}

A- Basic sample: The basic sample of the study included (10) experts in the field of sustainable professional development from the employees of the teacher professional academy with a percentage (10\%) of the study population, who were randomly selected.

B- $\quad$ The basic study sample included (400) teachers at a percentage (10\%) of the total teachers in the Directorate of Education in Port Said Governorate from the primary, middle and high school levels from the study population, who were chosen randomly.

C- $\quad$ The basic study sample included (20) directors and agents at a percentage (10\%) of the total directors and agents in the Directorate of Education in Port Said Governorate from the elementary, middle and high school levels, who were chosen randomly. B- The exploratory sample: .. The exploratory study sample included (5) experts in the field of sustainable professional development from among the employees of the teacher professional academy at a percentage $(5 \%)$ of the study population.

D- The pilot study sample included (500) teachers at a percentage (5\%) of the total number of teachers in the Directorate of Education in Port Said Governorate from the primary, middle and secondary levels of the study population.

E- The sample of the pilot study included (45) directors and agents at a percentage (5\%) of the total directors and agents in the Directorate of Education in Port Said Governorate from the primary, middle and high school levels.

\section{Data collection tools:}

The researcher used a data collection tool represented in the standardized interview with the main sample (teachers, administrators and agents, education experts) under study by designing a questionnaire containing open-ended questions aimed at identifying the current axes of professional development for teachers, the reality of the cultural role of teachers, the cultural role For teachers in the field of professional development for the sake of heritage preservation. I also aimed to identify the sources of activating the cultural role of teachers in the field of sustainable professional development for the sake of heritage preservation. 


\section{- data analysis:}

The researcher analyzed the content of the data that he reached through basic and surveys studies.

Presentation and discussion of results:

Presentation and discussion of the results of the first question:

After reviewing the axes of the strategic plan for the professional development of teachers for the year (2013), where it was found that the sustainable professional development plan includes the specialized academic dimension and the educational dimension, and by examining the documents of the national standards practices in the indicator of sustainable development for teachers in pre-university education institutions. Professional development is academic and educational, and thus the first question has been answered, which came a text on what are the current sustainable professional development axes among teachers.

\section{Presentation and discussion of results:}

\section{Presentation and discussion of the results of the second question:}

The results of the basic study came in agreement with the survey study on teachers at a rate of (20\%). The general cultural dimension related to heritage must be added to professional development programs for teachers, and the results of the basic study came in agreement with the results of the exploratory study of directors and agents at different stages in pre-university education institutions with an agreement ( $100 \%)$ the weakness of the cultural role of teachers and thus the second question has been answered, which came a text on what is the reality of the cultural dimension in the field of professional development for teachers.

\section{Presentation and discussion of the results of the third question:}

The result of the basic study came to education experts. The teacher must work on selfdevelopment by reading, knowing and attending cultural forums, and enriching the cultural dimension within the school that includes the material civilization represented in the facilities, buildings and sites, and the dimension that includes the living civilization represented in music, crafts, arts and poetry through holding seminars And activating the holding of exhibitions, poetry and painting competitions, and organizing field visits to archaeological sites for students. Thus, the third question has been answered, which came a text on what is the cultural role of teachers in the field of professional development in order to preserve the heritage from the viewpoint of education experts.

\section{Presentation and discussion of the results of the fourth question:}

The results of the basic study came to education experts regarding the sources of activating the cultural role of teachers: 
First: Consolidating the concept of the general cultural role and the cultural role related to the civilizational and natural heritage in the sustainable professional development programs for teachers: - Including the strategic plan for the school training units with training that includes the general cultural dimension related to the cultural and natural heritage - The use of academics in the field of culture and heritage with teacher training

Second : Providing sustainable professional development programs for student teachers in the College of Education that includes the cultural dimension related to heritage:

- Considering the general cultural dimension related to heritage as one of the most important goals that the Faculties of Education seek to achieve.

- Formulating an educational vision for an educational environment that supports general cultural awareness related to valuable heritage and sustainable development issues.

Creating cultural curricula that serve the concept of heritage and methods of preserving it.

Providing training programs for students aimed at activating volunteer activities in the field of heritage preservation.

The strategic plan includes the cultural dimension related to heritage and providing the necessary training for that.

Third: Activating the role of education departments by providing sustainable development programs that contain the cultural dimension related to the cultural and natural heritage:

- Holding workshops between training units in educational administrations and academics in the field of culture and heritage to create training programs that enhance the cultural dimension of teachers.

- Issuing decisions regarding the necessity of activating leadership classes and activity sessions on the concept of general culture related to heritage among students.

Fourth: Activating the role of civil society institutions in community participation programs in supporting cultural programs in the field of sustainable development:

- $\quad$ Pre-university education institutions should seek to extend the invitation to civil society institutions working in the field of culture and heritage. To hold seminars and courses for teachers to enhance the cultural dimension.

Directing invitations to the professors of the Faculties of Archeology, Arts and Tourism to hold seminars for students to enhance the cultural dimension and the principle of citizenship. Fifthly : Activating the role of school activities towards sustainable development issues:

- The extra-curricular activities plan includes activities that promote the principle of citizenship through cultural activities and activities related to heritage culture and how to preserve it. 
The activity and reserve quotas are allocated to general cultural programs linked to heritage.

Sixth : Highlighting the teacher's role in self-development to develop his cultural skills:

- Promoting the teacher's scientific and cultural trips with his students.

- Enhancing the teacher's visit with his students, cultural centers and archaeological sites.

- Motivating teachers to practice the cultural role and providing incentives.

- Encouraging teachers to learn about the most important developments in modern cultures.

- Holding workshops for teachers among themselves to exchange cultural information.

- Developing the skill of self-development in research, analysis, investigation and publication of relevant research for sustainable development.

Thus, the fourth question was answered, which came as a text on what are the sources of activating the cultural role of the teacher in the field of sustainable professional development in order to preserve the heritage from the viewpoint of education experts.

\section{Recommendations:}

1- Disseminating cultural values and preserving the culture and identity of the society is done through education through the teacher, which requires that he have a high level of knowledge of the society's culture and cultural challenges.

2- Inclusion of the general cultural dimension in teachers 'professional development training.

3- The cultural dimension has been included in the professional development training of teachers in order to preserve the heritage, whether cultural heritage or natural heritage.

\section{References:}

1- Al Hoshani, Mona Muhammad Suleiman (2016), a proposed conception of activating the cultural role of the teacher in light of the trends of education for sustainable development: a field study, a master's thesis, College of Education, Qassim University, Saudi Arabia.

2- Khawaldeh, Tayseer Muhammad (2012AD), school teachers' awareness of the components of Education for Sustainable Development (ESD), Mu'tah Journal for Research and Studies, Humanities and Social Sciences, Vol. 28, No. 5, Jordan.

3- Al-Sisi, Jamal Ahmed (2009), Some of the Roles of General Secondary Education Teachers in Light of the Challenges of Globalization and the Reality of Their Performance from Their Point of View and the Officials in Menoufia Governorate, Journal of the College of Education, Zagazig, P (63), C (1), April.

4- Al-Shehri, Muhammad Ahmad Abdo Yahya (2012 AD), the extent of the secondary school teacher's contribution to facing the cultural challenges of globalization (field study from the viewpoint of teachers and educational supervisors in the Education Department in Mahayel 
Asir Governorate, Master Thesis, College of Education, Umm Al-Qura University.

5- Al-Osaimi, Khaled Muhammad (2009), Contemporary global variables and their impact on teacher training, the thirteenth secondary meeting, Saudi Society for Educational and Psychological Sciences, King Saud University, Riyadh.

6- UNESCO (2000), United Nations Decade of Education for Sustainable Development, United Nations Educational and Cultural Sciences Organization, Paris.

7- UNESCO (2012), Education for Sustainable Development, Reference Book, United Nations Educational and Cultural Sciences Organization, Paris.

8- Imbaba, Mahajat Imam (12), the domains are double-distinguished in nature and in urban areas, an entrance to development to maintain development. The domains are dual distinctions in nature and construction. Entrance to development and preservation: With a special mention of the Nile front in Luxor, a master's thesis, Faculty of Engineering, Cairo University.

9- Hasan, Awatif Muhammad (1994 AD), The Cultural Preparation of the Teacher in the Faculties of Education, Journal of Educational Sciences, p (2). College of Education, University of Qena.

10- Ghashim, Muhammad Muhammad (2009), The role of the cultural component in preparing the teacher in light of contemporary variables, Education Message PBU (16), September, Sultanate of Oman.

11- Corney, Graham (2006). Education for Sustainable Development: An Empirical Study of the Tensions and Challenges Faced by Geography Student Teachers, International Research in Geographical and Environmental Education, Vol. 15, No. 3

12- Council of Ministers of Education (2012). Education for Sustainable Development in Canada: Facilities of Education, Council of Ministers of Education, Toronto Ontario, Canada. 13- HarshaDhar, G. and Shashirekha, KR (2015). The Role of Women Education for a Sustainable Development of the Balanced Society, Social Science Research Network.

14- Mshebila, E .(2012). Girl-Child/ Women Education for Sustainable Development in Nigeria, Journal of Education and Leadership Development, Volume 4.

15- Villanen, Heli .(2014). Teachers' Reflections on aan Education for Sustainable Development Project. International Research Geographical and Environmental education, Volume 23, Issue 2, 3 April.

16- Hatem Tawfiq AHMED, REHABILITATION AND FUNCTIONALITY OF ARCHITECTURAL MONUMENTS TO PRESERVE THEM FROM DAMAGE

FACTORS, International Journal of Multidisciplinary Studies in Heritage Research, Vol. 2, No. 1, 2019, pp. 18-32. 
17- Doaa Mohamed TAHOON, Yasmine Sabry HEGAZI, RISK MANAGEMENT

STRATEGIES OF CULTURAL HERITAGE CASE STUDY: TEL BASTA

ARCHAEOLOGICAL SITE, International Journal of Multidisciplinary Studies in Heritage

Research, Vol. 2, No. 1, 2019, pp. 33-36.

18- Heba Ali Ahmed WAJIH, SAILING THE HERITAGE OF THE LAND OF DAHAB, NUBIA, THE SUN DOES NOT GO DOWN, International Journal of Multidisciplinary Studies in Heritage Research, Vol. 2, No. 1, 2019, pp. 37-41.

Received: August 30, 2019

Accepted: October 7, 2019 